\title{
Article
}

\section{Potential Inhibitor of COVID-19 Main Protease (Mpro) from Several Medicinal Plant Compounds by Molecular Docking Study}

\author{
Siti Khaerunnisa ${ }^{1, *}$, Hendra Kurniawan ${ }^{2,3 *}$, Rizki Awaluddin ${ }^{4}$, Suhartati Suhartati ${ }^{5}$, Soetjipto \\ Soetjipto ${ }^{1, *}$ \\ 1 Departement of Medical Biochemistry, Faculty of Medicine, Airlangga University, Surabaya, East Java, \\ Indonesia, 60132; st.khaerunnisa@fk.unair.ac.id; soetjipto@fk.unair.ac.id \\ 2 Departement of Medical and Surgical Nursing, Faculty of Health Science, University of Muhammadiyah \\ Jember, Jember, East Java, Indonesia, 68121; hendrakurniawan@unmuhjember.ac.id \\ 3 PhD Student, Tropical Disease Research Center, Faculty of Medicine. Khon Kaen University, Khon Kaen, \\ Thailand, 40002; hendrakurniawan@unmuhjember.ac.id \\ 4 Departement of Pharmacy, Faculty of Health Science, University of Darussalam Gontor, Ponorogo, East \\ Java, Indonesia, 63471; awaluddinrizki@gmail.com \\ 5 Departement of Medical Biochemistry, Faculty of Medicine, University of Wijaya Kusuma Surabaya, East \\ Java, Indonesia, 60225; tati_biokim@yahoo.co.id \\ * Correspondence: st.khaerunnisa@fk.unair.ac.id ；Tel.: +6281233118194 (S.K.); soetjipto@fk.unair.ac.id; \\ Tel.: +6281331340518 (S.S.); hendrakurniawan@unmuhjember.ac.id ; Tel.: +628113572277 (H.K.)
}

\begin{abstract}
COVID-19, a new strain of coronavirus (CoV), was identified in Wuhan, China, in 2019. No specific therapies are available and investigations regarding COVID-19 treatment are lacking. Liu et al. (2020) successfully crystallised the COVID-19 main protease (Mpro), which is a potential drug target. The present study aimed to assess bioactive compounds found in medicinal plants as potential COVID-19 Mro inhibitors, using a molecular docking study. Molecular docking was performed using Autodock 4.2, with the Lamarckian Genetic Algorithm, to analyse the probability of docking. COVID-19 Mpro was docked with several compounds, and docking was analysed by Autodock 4.2, Pymol version 1.7.4.5 Edu, and Biovia Discovery Studio 4.5. Nelfinavir and lopinavir were used as standards for comparison. The binding energies obtained from the docking of 6LU7 with native ligand, nelfinavir, lopinavir, kaempferol, quercetin, luteolin-7-glucoside, demethoxycurcumin, naringenin, apigenin-7-glucoside, oleuropein, curcumin, catechin, epicatechin-gallate, zingerol, gingerol, and allicin were -8.37, -10.72, -9.41, -8.58, -8.47, -8.17, -7.99, $7.89,-7.83,-7.31,-7.05,-7.24,-6.67,-5.40,-5.38$, and $-4.03 \mathrm{kcal} / \mathrm{mol}$, respectively. Therefore, nelfinavir and lopinavir may represent potential treatment options, and kaempferol, quercetin, luteolin-7glucoside, demethoxycurcumin, naringenin, apigenin-7-glucoside, oleuropein, curcumin, catechin, and epicatechin-gallate appeared to have the best potential to act as COVID-19 Mpro inhibitors. However, further research is necessary to investigate their potential medicinal use.
\end{abstract}

Keywords: COVID-2019; Mpro; 6LU7; Medicinal Plant Compounds; Docking

\section{Introduction}

Coronaviruses (CoVs) are an etiologic agent of severe infections in both humans and animals, which can cause disorder not only in the respiratory tract but also in the digestive tract and systemically. Previous studies of CoVs have reported that CoVs can infect certain species of animals, including mammals, avian species, and reptiles [1].

The new strain of CoV was identified at the end of 2019, initially named 2019-nCoV, and emerged during an outbreak in Wuhan, China [2]. The Emergency Committee of the World Health Organization (WHO) declared an outbreak in China on January 30, 2020, which was considered to be 
a Public Health Emergencies of International Concern (PHEIC) [3]. Officially, WHO named this CoV COVID-19 (coronavirus disease 2019), on February 11, 2020, based on consultations and collaborations with the World Organization for Animal Health and the Food and Agriculture Organization of the United Nations [4].

According to the current situational report from WHO, released on February 11, 2020, 43,103 COVID-19 cases have been confirmed globally, including 2,560 new cases. In China, the number of confirmed cases reached 42,708, including 2,484 new cases, 7,333 severe cases, and 1,017 deaths. Outside of China, 395 cases were confirmed in 24 countries, with 1 death [4].

Currently, no specific therapies for COVID-19 are available and investigations regarding the treatment of COVID-19 are lacking [3]. However, the measures that have been implemented remain limited to preventive and supportive therapies, designed to prevent further complications and organ damage [3]. Some preliminary studies have investigated potential combinations that include the protease inhibitor lopinavir/ritonavir, which is commonly used to treat human immunodeficiency virus (HIV)/acquired immunodeficiency syndrome patients, for the treatment of COVID-19-infected patients [5]. Other reported antiviral treatments form human pathogenic CoVs include nucleoside analogues, neuraminidase inhibitors, remdesivir, umifenovir (arbidol), tenofovir disoproxil (TDF), and lamivudine (3TC) [5]. A separate investigation performed by $\mathrm{Xu}$ et al. (2020) indicated that among 4 tested drugs (nelfinavir, pitavastatin, perampanel, and praziquantel), nelfinavir was identified as the best potential inhibitor against COVID-19 Mpro, based on binding free energy calculations using the molecular mechanics with generalised Born and surface area solvation (MM/GBSA) model and solvated interaction energy (SIE) methods [6].

The results from preliminary studies remain unapproved for therapeutic use in clinical settings for the treatment of COVID-19-infected patients [5, 7]. Liu et al. (2020) have successfully crystallised the main protease (Mpro)/chymotrypsin-like protease (3CL ${ }^{\text {pro }}$ ) from COVID-19, which has been structured and repositioned in the Protein Data Bank (PDB) and is accessible by the public. This protease represents a potential target for the inhibition of CoV replication [6].

Environmental factors can greatly influence the secretion of secondary metabolites from tropical plants. Therefore, great attention has been paid to the secondary metabolites secreted by plants in tropical regions that may be developed as medicines $[8,9]$. Several compounds, such as flavonoids, from medicinal plants, have been reported to have antiviral bioactivities [10-12]. In the present study, we investigated kaempferol, quercetin, luteolin-7-glucoside, demethoxycurcumin, naringenin, apigenin-7-glucoside, oleuropein, curcumin, catechin, epicatechin-gallate, zingerol, gingerol, and allicin as potential inhibitor candidates for COVID-19 Mpro. The findings of the present study will provide other researchers with opportunities to identify the right drug to combat COVID-19.

\section{Experimental Section}

\section{Proteins/Macromolecules}

COVID-19 3clpro/Mpro (PDB ID: 6LU7) [13] and 3clpro/Mpro (PDB ID: 2GTB) [6] structures were obtained from PDB (https://www.rcsb.org/), in .pdb format. PDB is an archive for the crystal structures of biological macromolecules, worldwide [14].

The 6LU7 protein contains two chains, A and B, which form a homodimer. Chain A was used for macromolecule preparation. The native ligand for 6LU7 is $\underline{n-[(5-m e t h y l i s o x a z o l-3-}$ yl)carbonyl]alanyl-1-valyl-n 1 -((1r,2z)-4-(benzyloxy)-4-oxo-1-\{[(3r)-2-oxopyrrolidin-3yl]methyl\}but-2-enyl)-1-leucinamide.

\section{Ligand and Drug Scan}

The 3-dimensional (3D) structures were obtained from PubChem (https://pubchem.ncbi.nlm.nih.gov/), in .sdf format. PubChem is a chemical substance and biological activities repository consisting of three databases, including substance, compound, and bioassay databases [15]. Several ligands for which the active compound can be found in herbal medicine were 
downloaded from Dr. Duke's Phytochemical and Ethnobotanical Databases (https:/phytochem.nal.usda.gov/phytochem/search/list). The compounds used in the present study were nelfinavir (CID_64143), lopinavir (CID_92727), luteolin-7-glucoside (CID_5280637), demethoxycurcumin (CID_5469424), apigenin-7-glucoside (CID_5280704), oleuropein (CID_56842347), curcumin (CID_969516), epicatechin-gallate (CID_107905), zingerol (CID_3016110), gingerol (CID_442793), catechin (CID_9064), and allicin (CID_65036), quercetin (CID_5280343), kaempferol (CID_5280863) and naringenin (CID_439246).

Drug-like properties were calculated using Lipinski's rule of five, which proposes that molecules with poor permeation and oral absorption have molecular weights $>500, \mathrm{C} \log P>5$, more than 5 hydrogen-bond donors, and more than 10 acceptor groups [16, 17] Adherence with Lipinski's rule of five as calculated using SWISSADME prediction (http://www.swissadme.ch/).

\section{Determination of Active Sites}

The amino acids in the active site of a protein were determined using the Computed Atlas for Surface Topography of Proteins (CASTp) (http://sts.bioe.uic.edu/castp/index.html?2011) and Biovia Discovery Studio 4.5. The determination of the amino acids in the active site was used to analyse the Grid box and docking evaluation results. Discovery Studio is an offline life sciences software that provides tools for protein, ligand, and pharmacophore modelling [18].

\section{Molecular Docking}

Ligand optimisation was performed by Avogadro version 1.2, with Force Field type MMFF94, and saved in .mol2 format. Autodock version 4.2 used for protein optimisation, by removing water and other atoms, and then adding a polar hydrogen group. Autodock 4.2 was supported by Autodock tools, MGL tools, and Rasmol. Autogrid then determined the native ligand position on the binding site by arranging the grid coordinates (X, Y, and Z). Ligand tethering of the protein was performed by regulating the genetic algorithm (GA) parameters, using 10 runs of the GA criteria. The docking analyses were performed by both Autodock 4.2, Pymol version 1.7.4.5 Edu and Biovia Discovery Studio 4.5 .

\section{Results}

Table 1 shows the structures and amino acids found in the active site pockets of 6LU7 and 2GTB. 6LU7 is the main protease (Mpro) found in COVID-19, which been structured and repositioned in PDB and can be accessed by the public, as of early February 2020.

$2 \mathrm{GTB}$ is the main protease found in the $\mathrm{CoV}$ associated with the severe acute respiratory syndrome (SARS), which can be accessed in PDB and was suggested to be a potential drug target for 2019-nCov [6]. Xu et al. (2020) mentioned that the main protease in 2019-nCov shares 96\% similarity with that in SARS.

Table 1. Protein target structures and active site amino acids (Biovia Discovery Studio 4.5, 2019) and the native ligand structure

\begin{tabular}{|c|c|c|c|c|}
\hline No & $\begin{array}{c}\text { PDB } \\
\text { ID }\end{array}$ & Macromolecule & Native Ligand & Active site \\
\hline 1 & 6 LU7 & & THR24, THR26, PHE140, \\
ASN142, GLY143, CYS145, \\
HIS163, HIS164, GLU166, \\
HIS172
\end{tabular}




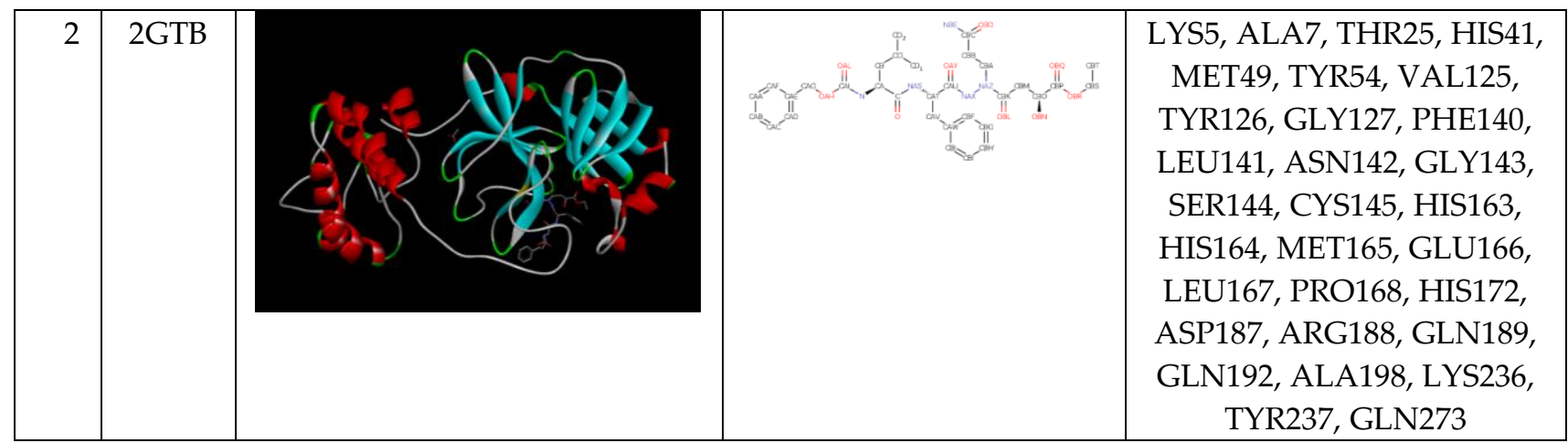

Ligands and several drug candidate compounds have been previously selected, based on adherence to Lipinski's rule of five. The selected ligands that did not incur more than 2 violations of Lipinski's rule could be used in molecular docking experiments with the target protein. The drug scanning results (Table 2) show that all tested compounds in this study were accepted by Lipinski's rule of five.

Table 2. Properties of COVID-19 Mpro potential inhibitor candidates

\begin{tabular}{|c|c|c|c|c|c|}
\hline \multirow[t]{2}{*}{ No } & \multirow[t]{2}{*}{ Compound } & \multirow{2}{*}{$\begin{array}{l}\text { Molecular } \\
\text { formula }\end{array}$} & \multirow{2}{*}{$\begin{array}{l}\text { Molecular structure and } \\
\text { Interaction with 6LU7 }\end{array}$} & \multicolumn{2}{|c|}{ Lipinski's rule of five } \\
\hline & & & & Properties & Value \\
\hline \multirow[t]{5}{*}{1} & \multirow[t]{5}{*}{ Lopinavir } & \multirow[t]{5}{*}{$\frac{\mathrm{C}_{37} \mathrm{H}_{48} \mathrm{~N}_{4} \mathrm{O}}{\underline{5}}$} & \multirow[t]{5}{*}{  } & $\begin{array}{c}\text { Molecular weight }(<500 \\
\text { Da) }\end{array}$ & 628.8 \\
\hline & & & & $\log P(<5)$ & 4.37 \\
\hline & & & & H-Bond donor (5) & 4 \\
\hline & & & & H-bond acceptor $(<10)$ & 5 \\
\hline & & & & Violations & 1 \\
\hline \multirow[t]{5}{*}{2} & \multirow[t]{5}{*}{ Nelfinavir } & \multirow[t]{5}{*}{$\frac{\mathrm{C}_{32} \mathrm{H}_{45} \mathrm{~N}_{3} \mathrm{O}}{\underline{4} \underline{\mathrm{S}}}$} & \multirow{5}{*}{  } & $\begin{array}{c}\text { Molecular weight }(<500 \\
\text { Da })\end{array}$ & 567.78 \\
\hline & & & & $\log P(<5)$ & 4.33 \\
\hline & & & & H-Bond donor (5) & 4 \\
\hline & & & & H-bond acceptor $(<10)$ & 5 \\
\hline & & & & Violations & 1 \\
\hline \multirow[t]{5}{*}{3} & \multirow[t]{5}{*}{$\begin{array}{l}\text { Luteolin-7- } \\
\text { glucoside }\end{array}$} & \multirow[t]{5}{*}{$\underline{\mathrm{C}_{21} \mathrm{H}_{20} \mathrm{O}_{11}}$} & \multirow[b]{5}{*}{ (ilis } & $\begin{array}{c}\text { Molecular weight }(<500 \\
\text { Da) }\end{array}$ & 448.38 \\
\hline & & & & $\log P(<5)$ & 0.16 \\
\hline & & & & H-Bond donor (5) & 7 \\
\hline & & & & H-bond acceptor $(<10)$ & 11 \\
\hline & & & & Violations & 2 \\
\hline \multirow[t]{4}{*}{4} & \multirow[t]{4}{*}{$\begin{array}{c}\text { Demethoxycur } \\
\text { cumin }\end{array}$} & \multirow[t]{4}{*}{$\underline{\mathrm{C}_{20} \mathrm{H}_{18} \mathrm{O}_{5}}$} & & $\begin{array}{c}\text { Molecular weight }(<500 \\
\text { Da) }\end{array}$ & 338.35 \\
\hline & & & & $\log P(<5)$ & 3 \\
\hline & & & & H-Bond donor (5) & 2 \\
\hline & & & & H-bond acceptor $(<10)$ & 5 \\
\hline
\end{tabular}




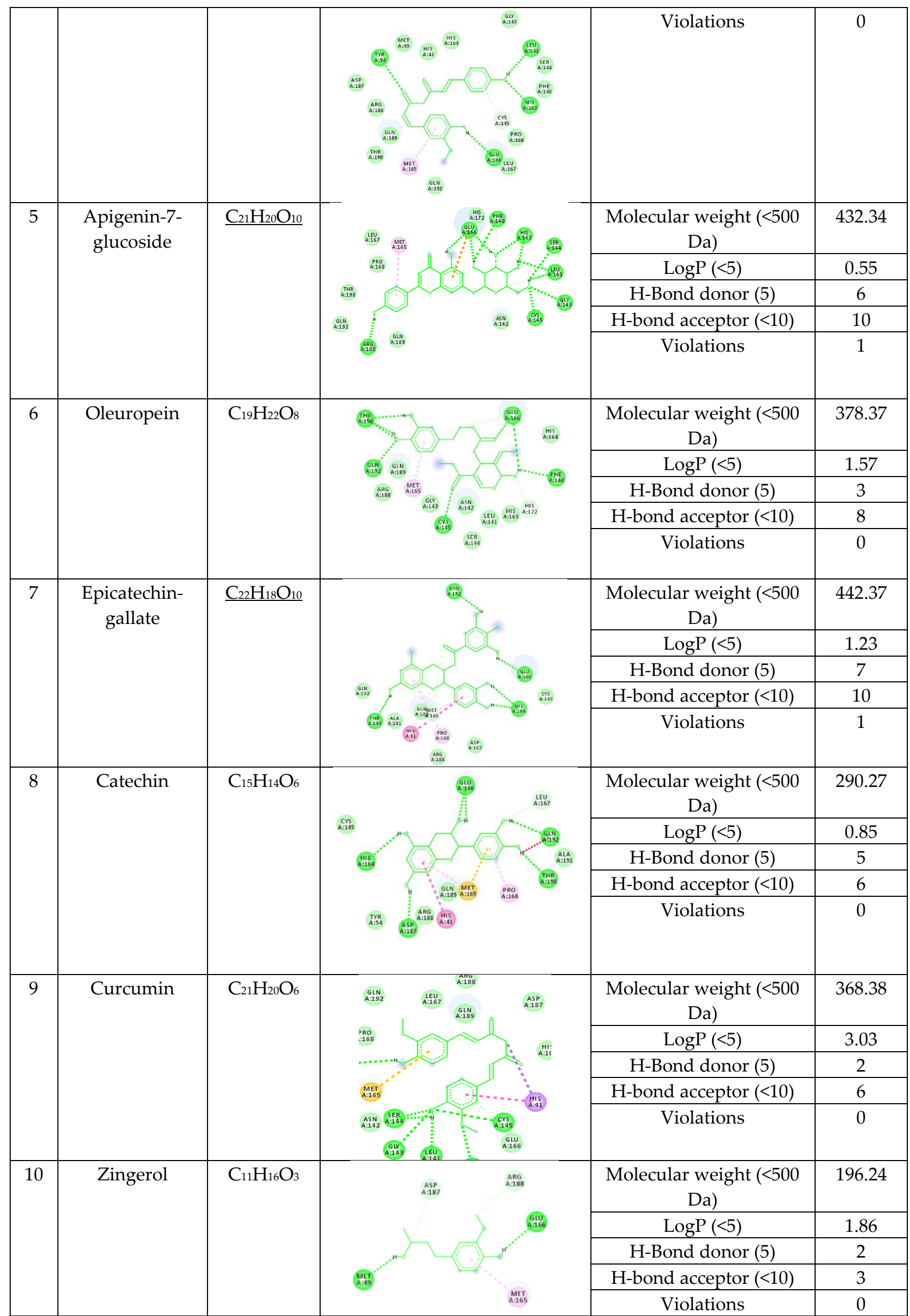


6 of 14

\begin{tabular}{|c|c|c|c|c|c|}
\hline \multirow[t]{5}{*}{11} & \multirow[t]{5}{*}{ Gingerol } & \multirow[t]{5}{*}{$\mathrm{C}_{17} \mathrm{H}_{26} \mathrm{O}_{4}$} & \multirow{5}{*}{ 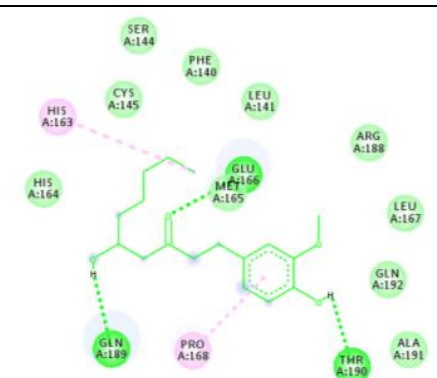 } & $\begin{array}{c}\text { Molecular weight }(<500 \\
\text { Da) }\end{array}$ & 294.39 \\
\hline & & & & $\log \mathrm{P}(<5)$ & 3.13 \\
\hline & & & & H-Bond donor (5) & 2 \\
\hline & & & & H-bond acceptor $(<10)$ & 4 \\
\hline & & & & Violations & 0 \\
\hline \multirow[t]{5}{*}{12} & \multirow[t]{5}{*}{ Allicin } & \multirow[t]{5}{*}{$\mathrm{C}_{6} \mathrm{H}_{10} \mathrm{OS}_{2}$} & \multirow[t]{5}{*}{$\begin{array}{l}\text { Asp } \\
\text { A:187 }\end{array}$} & $\begin{array}{c}\text { Molecular weight }(<500 \\
\text { Da) }\end{array}$ & 162.27 \\
\hline & & & & $\log \mathrm{P}(<5)$ & 1.61 \\
\hline & & & & H-Bond donor (5) & 0 \\
\hline & & & & H-bond acceptor $(<10)$ & 1 \\
\hline & & & & Violations & 0 \\
\hline \multirow[t]{5}{*}{13} & \multirow[t]{5}{*}{ Kaempferol } & \multirow[t]{5}{*}{$\mathrm{C}_{15} \mathrm{H}_{10} \mathrm{O}_{6}$} & & $\begin{array}{c}\text { Molecular weight }(<500 \\
\text { Da) }\end{array}$ & 286,24 \\
\hline & & & & $\log \mathrm{P}(<5)$ & 1,58 \\
\hline & & & & H-Bond donor (5) & 4 \\
\hline & & & & H-bond acceptor $(<10)$ & 6 \\
\hline & & & & Violations & 0 \\
\hline \multirow[t]{5}{*}{14} & \multirow[t]{5}{*}{ Quercetin } & \multirow[t]{5}{*}{$\mathrm{C}_{15} \mathrm{H}_{10} \mathrm{O}_{7}$} & \multirow[t]{5}{*}{$\begin{array}{l}610 \\
\text { (61166? }\end{array}$} & $\begin{array}{c}\text { Molecular weight }(<500 \\
\text { Da) }\end{array}$ & 302,24 \\
\hline & & & & $\log \mathrm{P}(<5)$ & 1,23 \\
\hline & & & & H-Bond donor (5) & 5 \\
\hline & & & & H-bond acceptor $(<10)$ & 7 \\
\hline & & & & Violations & 0 \\
\hline \multirow[t]{5}{*}{15} & \multirow[t]{5}{*}{ Naringenin } & \multirow[t]{5}{*}{$\mathrm{C}_{15} \mathrm{H}_{12} \mathrm{O}_{5}$} & \multirow[t]{5}{*}{ 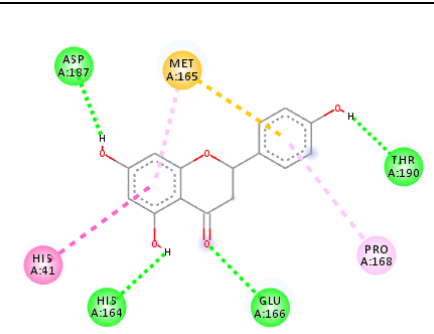 } & $\begin{array}{c}\text { Molecular weight }(<500 \\
\text { Da) }\end{array}$ & 272,25 \\
\hline & & & & $\log \mathrm{P}(<5)$ & 1,84 \\
\hline & & & & H-Bond donor (5) & 3 \\
\hline & & & & H-bond acceptor $(<10)$ & 5 \\
\hline & & & & Violations & 0 \\
\hline
\end{tabular}

Table 3 shows the molecular docking analysis results for several compounds against 6LU7, including binding energy/Gibbs Energy, ligand efficiency, inhibition constant, intermolecular energy, and van der Waals (VDW)-H Bond desolvation energy. 
Table 3. Molecular docking analysis of several compounds against 6LU7

\begin{tabular}{|c|c|c|c|c|c|c|}
\hline Protein & Ligand Properties & $\begin{array}{c}\text { Binding } \\
\text { Energy } \\
(\Delta G)\end{array}$ & $\begin{array}{c}\text { Ligand } \\
\text { Efficienc } \\
\mathbf{y} \\
\end{array}$ & $\begin{array}{l}\text { Inhibition } \\
\text { Constant }\end{array}$ & $\begin{array}{c}\text { Intermole } \\
\text { cular } \\
\text { Energy }\end{array}$ & $\begin{array}{c}\text { VDW-H Bond } \\
\text { Desolvation } \\
\text { Energy } \\
\end{array}$ \\
\hline \multirow[t]{16}{*}{ 6LU7 } & Native Ligand & -8.37 & -0.17 & $736.89 \mu \mathrm{M}$ & -14.33 & -14.33 \\
\hline & Nelfinavir & -10.72 & -0.27 & $13.91 \mathrm{nM}$ & -14.3 & -13.83 \\
\hline & Lopinavir & -9.41 & -0.2 & $126.76 \mu \mathrm{M}$ & -14.18 & -13.83 \\
\hline & Kaempferol & $-8,58$ & $-0,41$ & $516,02 \mathrm{nM}$ & $-10,07$ & $-9,88$ \\
\hline & Quercetin & $-8,47$ & $-0,39$ & $618,19 \mathrm{nM}$ & $-10,26$ & $-10,06$ \\
\hline & $\begin{array}{l}\text { Luteolin-7- } \\
\text { glucoside }\end{array}$ & -8.17 & -0.26 & $1.03 \mu \mathrm{M}$ & -11.45 & -11.38 \\
\hline & $\begin{array}{c}\text { Demetoxycurcumin } \\
\mathrm{e}\end{array}$ & -7.99 & -0.32 & $1.38 \mu \mathrm{M}$ & -10.68 & -10.59 \\
\hline & Naringenin & $-7,89$ & $-0,39$ & $1,64 \mathrm{uM}$ & $-9,09$ & $-8,97$ \\
\hline & $\begin{array}{l}\text { Apigenine-7- } \\
\text { glucoside }\end{array}$ & -7.83 & -0.25 & $1.81 \mu \mathrm{M}$ & -10.82 & -9.92 \\
\hline & Oleuropein & -7.31 & -0.27 & $4.4 \mu \mathrm{M}$ & -10.59 & -10.28 \\
\hline & Catechin & -7.24 & -0.34 & $4.95 \mu \mathrm{M}$ & -9.03 & -8.78 \\
\hline & Curcumin & -7.05 & -0.26 & $6.82 \mu \mathrm{M}$ & -10.03 & -9.88 \\
\hline & Epicatechin-gallate & -6.67 & -0.21 & $13.0 \mu \mathrm{M}$ & -9.95 & -9.51 \\
\hline & Zingerol & -5.40 & -0.38 & $112.22 \mu \mathrm{M}$ & -7.18 & -7.1 \\
\hline & Gingerol & -5.38 & -0.26 & $113.91 \mu \mathrm{M}$ & -8.96 & -8.82 \\
\hline & Allicin & -4.03 & -0.45 & $1.11 \mathrm{mM}$ & -5.52 & -5.51 \\
\hline
\end{tabular}



Figure 1. Histogram showing molecular docking results between 6LU7 and several drug candidate compounds (the binding energy value $\Delta \mathrm{G}$ is shown in minus $\mathrm{kcal} / \mathrm{mol}$ ) 



Figure 2. Docking analysis visualisation of 6LU7 binding with nelfinavir (A), lopinavir (B), luteolin7-glucoside $(\mathrm{C})$, apigenin-7-glucoside $(\mathrm{D})$, oleuropein $(\mathrm{E})$, demethoxycurcumin $(\mathrm{F})$, curcumin $(\mathrm{G})$, catechin $(\mathrm{H})$, epicatechin-gallate $(\mathrm{I})$, quercetin $(\mathrm{J})$, kaempferol $(\mathrm{K})$ and naringenin $(\mathrm{L})$ using Pymol. The yellow dots show H-bonds.

Figure 2 (A to I) visualises the binding between 6LU7 and several compounds, including nelfinavir, lopinavir, luteolin-7-glucoside, apigenin-7-glucoside, oleuropein, demethoxycurcumin, curcumin, catechin, epicatechin-gallate, quercetin, kaempferol, and naringenin as potential inhibitor of COVID-19 Mpro.

\section{Discussion}

Coronaviruses (CoVs) belong to a group of viruses that can infect humans and vertebrate animals. CoV infections affect the respiratory, digestive, liver, and central nervous systems of humans and animals [19]. The present study focused on the main proteases in CoVs (3CLpro/Mpro), especially PDB ID 6LU7, as potential target proteins for COVID-19 treatment. 6LU7 is the Mpro in COVID-19 
that has been structured and repositioned in PDB and has been accessible by the public since early February 2020. The Mpro of 2019-nCov shares $96 \%$ similarity with the Mpro of the SARS-CoV [6, 20]. The $\mathrm{M}$ pro in $\mathrm{CoV}$ is essential for the proteolytic maturation of the virus and has been examined as a potential target protein to prevent the spread of infection by inhibiting the cleavage of the viral polyprotein [13]. The discovery of the Mpro protease structure in COVID-19 provides a great opportunity to identify potential drug candidates for treatment.

Proteases represent potential targets for the inhibition of $\mathrm{CoV}$ replication, and the protein sequences of the SARS-CoV Mpro and the 2019-nCoV Mpro are $96 \%$ identical, and the active sites in both proteins remain free from mutations. The Mpro amino acids Thr24, Thr26, and Asn119 are predicted to play roles in drug interactions [21]. The disruption of protease activity can lead to various diseases; thus, commonly, host proteases can be used as potential therapeutic targets. In many viruses, proteases play essential roles in viral replication; therefore, proteases are often used as protein targets during the development of antiviral therapeutics [22].

Nelfinavir and lopinavir are protease inhibitors with high cytotoxic values against cells infected with HIV. Lopinavir and ritonavir are protease inhibitors recommended for the treatment of SARS and MERS, which have similar mechanisms of action as HIV [23]. The antiviral effects of nelfinavir against $\mathrm{CoV}$ have been studied in vitro, in Vero cells infected with SARS-CoV [24]. The IC50 value for nelfinavir in SARS-CoV is $0.048 \mu \mathrm{M}$ [25]. In the present study, we used nelfinavir and lopinavir as drug standards for comparison.

Several compounds, such as flavonoids, from medicinal plants, have been reported to show antiviral bioactivities [10-12]. We investigated kaempferol, quercetin, luteolin-7-glucoside, demethoxycurcumin, naringenin, apigenin-7-glucoside, oleuropein, curcumin, catechin, epicatechingallate, zingerol, gingerol, and allicin as potential inhibitors of the COVID-19 Mpro. An in silico analysis study showed that the compounds share a similar pharmacophore as nelfinavir. Several studies have investigated the presence of high numbers of these phenolic compounds belonging several medicinal plant which abundant in nature (see Table 4).

The binding energies obtained from docking 6LU7 with the native ligand, nelfinavir, lopinavir, kaempferol, quercetin, luteolin-7-glucoside, demethoxycurcumin, naringenin, apigenine-7-glucoside, oleuropein, curcumin, catechin, epicatechin-gallate, zingerol, gingerol, and allicin were $-8.37,-10.72$, $-9.41,-8.58,-8.47,-8.17,-7.99,-7.89,-7.83,-7.31,-7.05,-7.24,-6.67,-5.40,-5.38,-5.40$, and $-4.03 \mathrm{kcal} / \mathrm{mol}$, respectively (see Table 3 and Figure 1).

Table 4. Source of several compounds belong to medicinal plants

\begin{tabular}{llll}
\hline \multicolumn{1}{c}{ Compounds } & \multicolumn{1}{c}{ Sources } & \multicolumn{1}{c}{ Species name } & Reference \\
\hline Kaempferol & Spinach & Spinacia oleracea & {$[26]$} \\
& Cabbage & Brassica oleracea & {$[26]$} \\
& Dill & Anethum graveolens & {$[26]$} \\
& Chinese cabbage & Brassica rapa & {$[26]$} \\
& Katuk & Sauropus androgynus & {$[27]$} \\
\hline Quercetin & Dill & Anethum graveolens & {$[26]$} \\
& Fennel leaves & Foeniculum vulgare & {$[26]$} \\
& Onion & Allium cepa & {$[26]$} \\
& Oregano & Oregano vulgare & {$[26]$} \\
& Chili pepper & Capsicum annum & {$[26]$} \\
\hline Luteolin-7-glucoside & Olive & Olea Europaea $\mathrm{L}$ & {$[28-30]$} \\
& Star fruit & Averrhoa belimbi & {$[31]$} \\
& Chili pepper & Capsicum annum & {$[31]$} \\
& Welsh onion & / Allium fistulosum & {$[31]$} \\
& Leek & & \\
\hline
\end{tabular}




\begin{tabular}{llll}
\hline Demethoxycurcumine & Turmeric & Curcuma longa & {$[32,33]$} \\
& Curcuma & Curcuma xanthorriza & {$[32,33]$} \\
\hline Naringenin & Citrus fruit & Citrus sinensis & {$[34]$} \\
\hline Apigenine-7-glucoside & Star fruit & Averrhoa belimbi & {$[31]$} \\
& Goji berries & Lycium chinense & {$[31]$} \\
& Celery & Apium graveolens & {$[31]$} \\
& Olive & Olea Europaea $\mathrm{L}$ & {$[28,29]$} \\
\hline Oleuropein & Olive & Olea Europaea $\mathrm{L}$ & {$[28-30]$} \\
\hline Catechin & Green tea & Camellia sinesis & {$[35-37]$} \\
\hline Curcumin & Turmeric & Curcuma longa & {$[38-41]$} \\
& Curcuma & Curcuma xanthorriza & {$[32],[33]$} \\
\hline Epicatechin gallate & Green tea & Camellia sinesis & {$[35-37]$} \\
\hline Zingerol & Ginger & Zingiber officiale & {$[42-44]$} \\
\hline Gingerol & Ginger & Zingiber officiale & {$[42-44]$} \\
\hline Allicin & Garlic & Allium sativum & {$[45-47]$} \\
\hline
\end{tabular}

The results of docking analysis (Table 2 and Figure 2) showed that nelfinavir forms H-bonds with the 6LU7 amino acids Glu166, Gln189, and Gln192 (Figure 2A). Lopinavir forms H-bonds with the 6LU7 amino acids Glu166, Arg188, and Gln189 (Figure 2B). Luteolin-7-glucoside and forms Hbonds with the 6LU7 amino acid Phe140, Cys145, His163, His164, and Thr190 (Figure 2C). Demethoxycurcumin forms H-bonds with the 6LU7 amino acids Phe140, Leu141, Gly143, Ser144, Cys145, His163, Glu166, and Arg188 (Figure 2D). Apigenin-7-glucoside forms H-bonds with the 6LU7 amino acids Phe140, Cys145, Glu166, Thr190, and Gln192 (Figure 2E). Oleuropein forms Hbonds with the 6LU7 amino acids Tyr54, Leu141, His163, and Glu166 (Figure 2F). Curcumin forms H-bonds with the 6LU7 amino acids Leu141, Gly143, Ser144, Cys145, and Thr190 (Figure 2G). Catechin forms H-bonds with the 6LU7 amino acids His164, Glu166, Asp187, Thr190, and Gln192 (Figure 2H). Epicatechin-gallat forms H-bonds with the 6LU7 amino acids Asn142, His164, Glu166, and Thr190 (Figure 2I). Quercetin forms H-bonds with the 6LU7 amino acid His164, Glu166, Asp187, Gln192, Thr190 (Figure 2J). Kaempferol forms H-bonds with the 6LU7 amino acid Tyr54, His164, Glu166, Apr187, Thr190 (Figure 2J). Naringenin forms H-bonds with the 6LU7 amino acid His164, Glu166, Asp187, Thr190 (Figure 2J). Docking analysis results, including the H-bonds that interact with 6LU7 amino acids, can be observed in Table 1. All of the H-bonds interacted with amino acids in the COVID-19 Mpro active site. The binding energy results are related to the number of H-bonds formed with the active site pocket of COVID-19 Mpro.
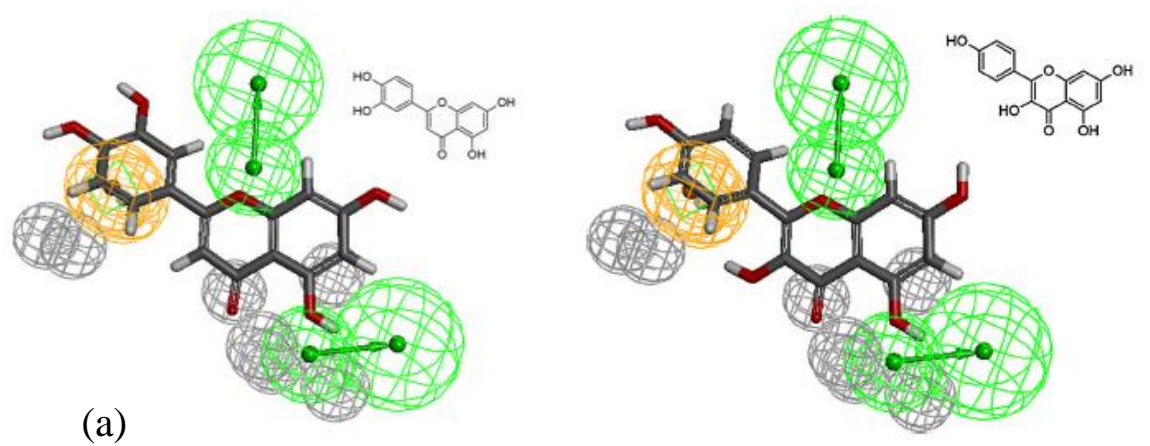

Figure 3. Luteolin-7-glucoside (aglycone) (a) and kaempferol (b) mapped to the pharmacophore model [48] 
Kaempferol and quercetin are a flavonol compounds, while luteolin-7-glucoside is a flavone within the class of flavonoid compounds [49]. Secondary metabolite compounds are commonly found in medicinal plants. Luteolin-7-glucoside and kaempferol shown in Figure 3, is a form of aglycone of flavonoid. Hydroxy groups $(-\mathrm{OH})$, ketone groups $(=\mathrm{O})$ and ether groups $(-\mathrm{O}-)$ in luteolin and kaempferol compounds are predicted to play roles amino acid residue interactions at the active site of COVID-19 Mpro [50].

The high affinity of drug compounds depends on the type and amount of bonding that occurs with the active site of the protein. In Table 2, nelfinavir forms many chemical bonds with 6LU7, including hydrogen bonds and hydrophobic bonds. Kaempferol, quercetin and luteolin-7-glucoside also forms many chemical bonds, similar to nelfinavir. Therefore, the affinity of kaempferol bonds is higher compared with other compounds.

The docking analysis in the present study showed the inhibition potential of several compounds, ranked by affinity $(\Delta \mathrm{G})$; nelfinavir $>$ lopinavir $>$ kaempferol $>$ quercetin $>$ luteolin-7-glucoside $>$ demethoxycurcumin $>$ naringenin $>$ apigenine-7-glucoside $>$ oleuropein $>$ curcumin $>$ catechin $>$ epigallocatechin $>$ zingerol $>$ gingerol $>$ allicin .

Kaempferol, quercetin, luteolin-7-glucoside, apigenin-7-glucoside, naringenin, oleuropein, demethoxycurcumin, curcumin, catechin, and epigallocatechin were the most recommended compounds found in medicinal plants as potential inhibitors of COVID-19 Mpro, which should be explored in future research.

\section{Conclusions}

Currently, COVID-19 has emerged in the human population, in China, and is a potential threat to global health, worldwide. However, no approved drug currently exists to treat the disease. The currently available drugs for COVID-19 treatment primarily act on the main protease (Mpro). The aim of this study was to examine several medicinal plant-derived compounds that may be used to inhibit the COVID-19 infection pathway. Nelfinavir, lopinavir, kaempferol, quercetin, luteolin-7-glucoside, demethoxycurcumin, naringenin, apigenin-7-glucoside, oleuropein, curcumin, catechin, and epicatechin-gallate have the lowest binding energies and inhibition constants. The affinity of kaempferol bonds is higher compared with other compounds. Therefore, we suggested that nelfinavir and lopinavir may represent potential treatment options, and kaempferol, quercetin, luteolin-7-glucoside, demethoxycurcumin, naringenin, apigenin-7-glucoside, oleuropein, curcumin, catechin, and epicatechin-gallate were the most recommended compounds found in medicinal plants that may act as potential inhibitors of COVID-19 Mpro. However, further research is necessary to investigate the potential uses of the medicinal plants containing these compounds.

Author Contributions: This study was conducted and conceptualization by SK, HK, RA, SH, SS ,; methodology by $\mathrm{SK}, \mathrm{SH}$ and $\mathrm{RA}$; installation software by $\mathrm{RA}$; validation by $\mathrm{SK}$ and $\mathrm{HK}_{\text {; }}$; formal analysis by RA and $\mathrm{SS}$; investigation by HK, SH, and SS,; resources by SK and SS,; data curation by SK, HK and RA,; writing-original draft preparation by SK, HK and RA,; writing-review and editing by SK, HK, RA, SH and SS,; visualization by SK and SS,; supervision by $\mathrm{HK}$ and RA,; project administration by SK,; funding acquisition by SS. All author have read and areed to the the published version of the manuscript.

Funding: This research was funded by a Grant-in-Aid from Dato' Sri Prof. Dr. Tahir for this research, through The Tahir Professorship Program, Indonesia

Acknowledgments: All the authors acknowledge and thank their respective Universities and for Dato' Sri Prof. Dr. Tahir for all supporting this research.

Conflicts of Interest: The authors declare no conflict of interest.

\section{References}

[1] W. Malik, Yashpal Singh; Sircar, Shubhankar; Bhat, Sudipta; Sharun, Khan; Dhama, Kuldeep; Dadar, Maryam; Tiwari, Ruchi; Chaicumpa, “Emerging novel Coronavirus (2019-nCoV) - Current scenario, evolutionary perspective based on genome analysis and recent developments," Vet. Q., vol. 40, no. 1, pp. 
1-12, 2020, doi: 10.1080/01652176.2020.1727993.

[2] P. R. Lee, Ping Ing; Hsueh, "Emerging threats from zoonotic coronaviruses-from SARS and MERS to 2019-nCoV," J. Microbiol. Immunol. Infect., pp. 1-3, 2020, doi: 10.1016/j.jmii.2020.02.001.

[3] P. Rodríguez-Morales, Alfonso J; MacGregor, Kirsten; Kanagarajah, Sanch; Patel, Dipti; Schlagenhauf, “Going global - Travel and the 2019 novel coronavirus," Travel Med. Infect. Dis., vol. 33, 2020, doi: https://doi.org/10.1016/j.tmaid.2020.101578.

[4] World Health Organization (WHO), “Novel Coronavirus ( 2019-nCoV ),” WHO Bull., no. JANUARY, pp. $1-7,2020$.

[5] H. Lu, “Drug treatment options for the 2019-new coronavirus (2019-nCoV)," Biosci. Trends, 2020, doi: 10.5582/bst.2020.01020.

[6] Z. Xu, C. Peng, Y. Shi, Z. Zhu, K. Mu, and X. Wang, “Nelfinavir was predicted to be a potential inhibitor of 2019-nCov main protease by an integrative approach combining homology modelling , molecular docking and binding free energy calculation," vol. 1201, pp. 0-2, 2020.

[7] M. L. Holshue et al., "First Case of 2019 Novel Coronavirus in the United States," N. Engl. J. Med., 2020, doi: 10.1056/nejmoa2001191.

[8] G. Guerriero et al., "Production of plant secondary metabolites: Examples, tips and suggestions for biotechnologists," Genes (Basel)., vol. 9, no. 6, pp. 34-46, 2018, doi: 10.3390/genes9060309.

[9] L. Yang, K. S. Wen, X. Ruan, Y. X. Zhao, F. Wei, and Q. Wang, "Response of plant secondary metabolites to environmental factors," Molecules, vol. 23, no. 4, pp. 1-26, 2018, doi: 10.3390/molecules23040762.

[10] H. Zakaryan, E. Arabyan, A. Oo, and K. Zandi, “Flavonoids: promising natural compounds against viral infections," Arch. Virol., vol. 162, no. 9, pp. 2539-2551, 2017, doi: 10.1007/s00705-017-3417-y.

[11] Thayil, M. Seema, and S. P. Thyagarajan, "Pa-9: A flavonoid extracted from plectranthus amboinicus inhibits HIV-1 protease," Int. J. Pharmacogn. Phytochem. Res., vol. 8, no. 6, pp. 1020-1024, 2016.

[12] S. Jo, S. Kim, D. H. Shin, and M. S. Kim, “Inhibition of SARS-CoV 3CL protease by flavonoids," J. Enzyme Inhib. Med. Chem., vol. 35, no. 1, pp. 145-151, 2020, doi: 10.1080/14756366.2019.1690480.

[13] R. X, Liu ; B, Zhang ; Z, Jin ; H, Yang ; Z, “The crytal structure of 2019-nCoV main protease in complex with an inhibitor N3," 2020.

[14] H. M. Berman et al., "The protein data bank," Acta Crystallogr. Sect. D Biol. Crystallogr., vol. 58, no. 6 I, pp. 899-907, 2002, doi: 10.1107/S0907444902003451.

[15] S. Kim et al., "PubChem substance and compound databases," Nucleic Acids Res., vol. 44, no. D1, pp. D1202-D1213, 2016, doi: 10.1093/nar/gkv951.

[16] C. A. Lipinski, F. Lombardo, B. W. Dominy, and P. J. Feeney, “Experimental and computational approaches to estimate solubility and permeability in drug discovery and development settings," Adv. Drug Deliv. Rev., vol. 64, no. SUPPL., pp. 4-17, 2012, doi: 10.1016/j.addr.2012.09.019.

[17] B. G. Giménez, M. S. Santos, M. Ferrarini, and J. P. Dos Santos Fernandes, "Evaluation of blockbuster drugs under the rule-of-five," Pharmazie, vol. 65, no. 2, pp. 148-152, 2010, doi: 10.1691/ph.2010.9733.

[18] G. S. B, L. Xavier, and S. Michael, “Molecular Docking Studies on Antiviral Drugs for SARS," vol. 5, no. 3, pp. 75-79, 2015.

[19] J. Xu, S. Zhao, T. Teng, A. E. Abdalla, and W. Zhu, “Systematic Comparison of Two Animal-to-Human Transmitted Human Coronaviruses : SARS-CoV-2 and,” 2020, doi: 10.3390/v12020244.

[20] A. Zhavoronkov et al., "Potential 2019-nCoV 3C-like Protease Inhibitors Designed Using Generative Deep Learning Approaches," no. February, 2020, doi: 10.26434/CHEMRXIV.11829102.V1.

[21] X. Liu and X.-J. Wang, "Potential inhibitors against 2019-nCoV coronavirus M protease from clinically 
approved medicines," J. Genet. Genomics, 2020, doi: 10.1016/j.jgg.2020.02.001.

[22] K. O. Chang, Y. Kim, S. Lovell, A. D. Rathnayake, and W. C. Groutas, "Antiviral drug discovery: Norovirus proteases and development of inhibitors," Viruses, vol. 11, no. 2, pp. 1-14, 2019, doi: 10.3390/v11020197.

[23] J.-Y. Li et al., "The epidemic of 2019-novel-coronavirus," Microbes Infect., 2019, doi: 10.1016/j.micinf.2020.02.002.

[24] N. Yamamoto et al., "HIV protease inhibitor nelfinavir inhibits replication of SARS-associated coronavirus," Biochem. Biophys. Res. Commun., vol. 318, no. 3, pp. 719-725, 2004, doi: 10.1016/j.bbrc.2004.04.083.

[25] L. E. Hsieh et al., "Synergistic antiviral effect of Galanthus nivalis agglutinin and nelfinavir against feline coronavirus," Antiviral Res., vol. 88, no. 1, pp. 25-30, 2010, doi: 10.1016/j.antiviral.2010.06.010.

[26] W. M. Dabeek and M. V. Marra, “Dietary quercetin and kaempferol: Bioavailability and potential cardiovascular-related bioactivity in humans," Nutrients, vol. 11, no. 10, 2019, doi: 10.3390/nu11102288.

[27] N. Andarwulan, R. Batari, D. A. Sandrasari, B. Bolling, and H. Wijaya, "Flavonoid content and antioxidant activity of vegetables from Indonesia," Food Chem., vol. 121, no. 4, pp. 1231-1235, 2010, doi: 10.1016/j.foodchem.2010.01.033.

[28] F. Nicolì et al., “Evaluation of phytochemical and antioxidant properties of 15 Italian olea europaea L. Cultivar Leaves," Molecules, vol. 24, no. 10, 2019, doi: 10.3390/molecules24101998.

[29] J. Meirinhos et al., "Analysis and quantification of flavonoidic compounds from Portuguese olive (olea europaea L.) leaf cultivars," Nat. Prod. Res., vol. 19, no. 2, pp. 189-195, 2005, doi: 10.1080/14786410410001704886.

[30] A. Lama-Muñoz, M. Del Mar Contreras, F. Espínola, M. Moya, I. Romero, and E. Castro, “Optimization of oleuropein and luteolin-7-o-glucoside extraction from olive leaves by ultrasound-assisted technology," Energies, vol. 12, no. 13, 2019, doi: 10.3390/en12132486.

[31] H. A. Omar, K. Abboud, N. Cheng, K. R. Malekshan, A. T. Gamage, and W. Zhuang, “Miean, K. H., \& Mohamed, S. (2001). Flavonoid (myricetin, quercetin, kaempferol, luteolin, and apigenin) content of edible tropical plants.," J. Agric. food Chem. 49(6), 3106-3112., vol. 18, no. 4, pp. 2315-2344, 2016, doi: 10.1109/COMST.2016.2554098.

[32] B. Cahyono, J. Ariani, H. Failasufa, M. Suzery, S. Susanti, and H. Hadiyanto, “Extraction of homologous compounds of curcuminoid isolated from temulawak (Curcuma xanthorriza roxb.) plant," Rasayan J. Chem., vol. 12, no. 1, pp. 7-13, 2019, doi: 10.31788/RJC.2019.1213092.

[33] A. Rosidi, A. Khomsan, B. Setiawan, H. Riyadi, and D. Briawan, “Antioxidant potential of temulawak (Curcuma xanthorrhiza roxb)," Pakistan J. Nutr., vol. 15, no. 6, pp. 556-560, 2016, doi: 10.3923/pjn.2016.556.560.

[34] B. Salehi et al., "The therapeutic potential of naringenin: A review of clinical trials," Pharmaceuticals, vol. 12, no. 1, pp. 1-18, 2019, doi: 10.3390/ph12010011.

[35] M. P. M. De Maat, H. Pijl, C. Kluft, and H. M. G. Princen, “Consumption of black and green tea has no effect on inflammation, haemostasis and endothelial markers in smoking healthy individuals," Eur. J. Clin. Nutr., vol. 54, no. 10, pp. 757-763, 2000, doi: 10.1038/sj.ejcn.1601084.

[36] D. Rahardiyan, "Antibacterial potential of catechin of tea (Camellia sinensis) and its applications," Food Res., vol. 3, no. 1, pp. 1-6, 2019, doi: 10.26656/fr.2017.3(1).097.

[37] R. M. M. De Oliveira, “Quantification of catechins and caffeine from green tea (Camellia sinensis) infusions, extract, and ready-to-drink beverages," Food Sci. Technol., vol. 32, no. 1, pp. 163-166, 2012, doi: 
10.1590/s0101-20612012005000009.

[38] I. C. Chao, C. M. Wang, S. P. Li, L. G. Lin, W. C. Ye, and Q. W. Zhang, "Simultaneous quantification of three curcuminoids and three volatile components of curcuma longa using pressurized liquid extraction and high-performance liquid chromatography," Molecules, vol. 23, no. 7, 2018, doi: 10.3390/molecules23071568.

[39] L. Narain and M. Pradesh-, “ISSN 2230 - 8407 QUALITATIVE AND QUANTITATIVE PROFILE OF CURCUMIN FROM ETHANOLIC EXTRACT OF CURCUMA LONGA Soni Himesh *, Patel Sita Sharan, Mishra K, Nayak Govind , Singhai AK," Int. Res. J. Pharm., vol. 2, no. 4, pp. 180-184, 2011.

[40] W. Pothitirat and W. Gritsanapan, “Quantitative Analysis of Curcumin, Demethoxycurcumin and Bisdemethoxycurcumin in the Crude Curcuminoid Extract from Curcuma longa in Thailand by TLCDensitometry," Mahidol Univ. J. Pharm. Sci., vol. 32, no. Figure 1, pp. 23-30, 2005.

[41] S. Hewlings and D. Kalman, “Curcumin: A Review of Its' Effects on Human Health,” Foods, vol. 6, no. 10, p. 92, 2017, doi: 10.3390/foods6100092.

[42] L. L. Li et al., "Pharmacokinetics and tissue distribution of gingerols and shogaols from ginger (zingiber officinale rosc.) in rats by UPLC-Q-Exactive-HRMS," Molecules, vol. 24, no. 3, pp. 1-12, 2019, doi: 10.3390/molecules24030512.

[43] S. K. Sanwal, R. K. Yadav, P. K. Singh, J. Buragohain, and M. R. Verma, “Gingerol content of different genotypes of ginger (Zingiber officinale)," Indian J. Agric. Sci., vol. 80, no. 3, pp. 258-260, 2010.

[44] T. Chumroenphat, I. Somboonwatthanakul, L. Butkhup, and S. Saensouk, "6-gingerol content of ginger (Zingiber officinale Roscoe) by different drying metthods," Bot. Res. Trop. Asia, no. October, p. , 2015.

[45] N. Puvača et al., "Bioactive Compounds of Garlic, Black Pepper and Hot Red Pepper," XVI Int. Symp. “Feed Technol. Food Tech Congr., no. October, pp. 116-122, 2014, doi: 10.13140/2.1.1833.9526.

[46] A. Shang et al., "Bioactive compounds and biological functions of garlic (allium sativum L.)," Foods, vol. 8, no. 7, pp. 1-31, 2019, doi: 10.3390/foods8070246.

[47] I. C. F. R. F. Natalia Martins, Spyridon Petropoulos, "Chemical composition and bioactive compounds of garlic (," Thesis Rev., pp. 1-42, 2016.

[48] S. Ravichandran et al., "Pharmacophore model of the quercetin binding site of the SIRT6 protein," J. Mol. Graph. Model., vol. 49, pp. 38-46, 2014, doi: 10.1016/j.jmgm.2014.01.004.

[49] S. Soewono, Suhartati; Khaerunnisa, Flavonoid. Surabaya: Airlangga University Press, 2016.

[50] N. Aziz, M. Y. Kim, and J. Y. Cho, “Anti-inflammatory effects of luteolin: A review of in vitro, in vivo, and in silico studies," J. Ethnopharmacol., vol. 225, no. May, pp. 342-358, 2018, doi: 10.1016/j.jep.2018.05.019. 